\title{
Carnets
}

Revue électronique d'études françaises de l'APEF

Première Série - 4 Numéro Spécial | 2012

Invasions \& Évasions

\section{José Régio em França: um paradigma de diálogo em sentido único}

\section{Fernando Carmino Marques}

\section{(2) OpenEdition}

1 Journals

\section{Édition électronique}

URL : http://journals.openedition.org/carnets/7707

DOI : 10.4000/carnets. 7707

ISSN : 1646-7698

Éditeur

APEF

\section{Édition imprimée}

Date de publication : 1 juin 2012

Pagination : 219-231

\section{Référence électronique}

Fernando Carmino Marques, « José Régio em França: um paradigma de diálogo em sentido único », Carnets [En ligne], Première Série - 4 Numéro Spécial | 2012, mis en ligne le 23 juin 2018, consulté le 24 avril 2019. URL : http://journals.openedition.org/carnets/7707 ; DOI : 10.4000/carnets.7707

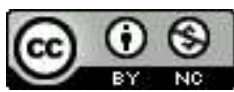

Carnets est mis à disposition selon les termes de la licence Creative Commons - Atribution - Pas d'utilisation commerciale 4.0 International. 


\title{
JOSÉ RÉGIO EM FRANÇA \\ Um paradigma de diálogo em sentido único
}

FERNANDO CARMINO MARQUES

Instituto Politécnico da Guarda

carmino@ipg.pt

\begin{abstract}
Résumé
L'œuvre de l'écrivain portugais José Régio n'a jamais trouvé en France l'accueil que son auteur pouvait attendre, lui qui fut l'un des plus fervents défenseurs de la culture française au Portugal pendant la première moitié du XXème siècle. Loin d'être un cas isolé, la réception faite à son œuvre met en évidence les limites que les préjugés culturels peuvent imposer au dialogue et au véritable échange interculturel. Grâce à l'analyse de la réception en France de l'œuvre de José Régio et les réactions qu'elle a provoquées, nous verrons comment le dialogue culturel peut être interrompu par l'absence de médiateurs réceptifs à la culture de l'autre, à sa différence et à son originalité.
\end{abstract}

\section{Abstract}

The goal of this paper is to demonstrate the reception given to the work of José Régio in France and the debate it provoked. A staunch defender of French culture, José Régio never found in France the voice that would allow himself to establish a true dialogue with the French reader. Far from being unique, his case is a model for reflection on the availability of culture receptive influential before the perceptual difference and the originality and cultural influence that each can bring. Through the analysis of the reception of José Régio's work in France, we will see how the much desired cultural dialogue can be interrupted by lack of culturally aware mediators.

Mots-clés: José Régio, réception, France, crítica.

Keywords: José Régio, reception, France, criticism. 
A obra do poeta português José Régio nunca encontrou em França o reconhecimento que se poderia esperar. Bom conhecedor da língua e da cultura francesa que diariamente divulgava, como professor de francês no liceu de Portalegre e nos artigos que ia publicando em diversas revistas nacionais, esperou mais de setenta anos para ver um livro seu editado em França. Publicada de forma descontínua, a recepção feita à sua obra revela, em geral, um permanente desconhecimento, não raro motivado por um a priori que em nada valoriza aqueles que dele fizeram uso. Afirmado isto, vejamos agora quando foi publicada e como foi interpretada a obra de José Régio em França. Para tal, mencionamos, primeiramente, as referências encontradas em diversas fontes: revistas, jornais, histórias da literatura, enciclopédicas, antologias e prefácio de edições; de seguida, passamos à respectiva análise. Deste modo, e segundo apuramos, José Régio aparece referenciado nas seguintes publicações:

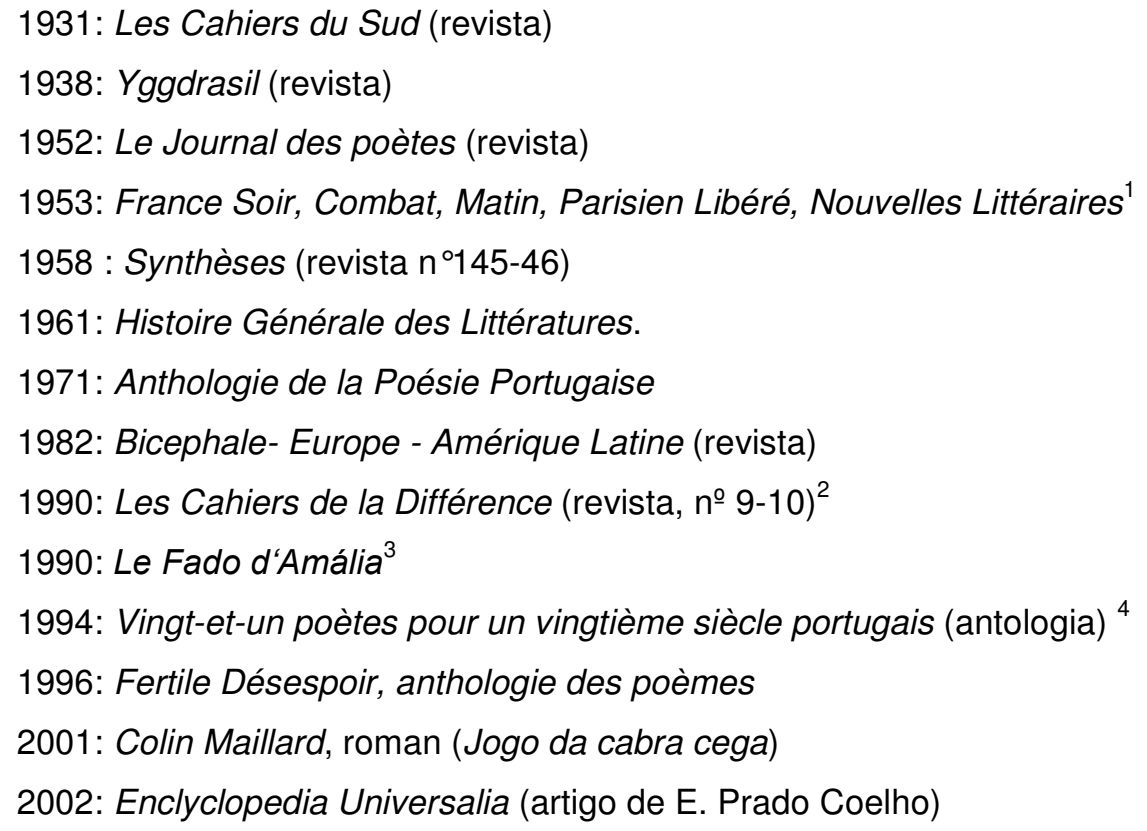

Vejamos agora as reações e os comentários que estas publicações suscitaram. Foi Pierre Hourcade que, em fevereiro de 1931, chamou, pela primeira vez, a atenção do público francês para a obra de José Régio. Num artigo intitulado Défense et Illustration de la poésie portugaise vivante, publicado pela prestigiada revista Cahiers du Sud, Pierre Hourcade (que escrevia para um leitor que ignorava quase tudo sobre literatura portuguesa) afirmava que a saudade obsessiva, aliada ao gosto da facilidade retórica, era o ópio do povo

\footnotetext{
1 Entre outros jornais, a propósito da representação de Jacob e o Anjo em Paris.

2 "Mário ou moi-même l'autre", épisode tragi-comique en un acte, traduit par Dominique Bussillet et Jorge Sedas Nunes, Paris, Cahiers de la Différence n9-10, 1990.

3 Antologia de poemas interpretados por Amália Rodrigues, editada pela editora Actes Sud.

4 "Vingt-et-un poètes pour un vingtième siècle portugais", Anthologie, Bordeaux, L'Escampette, 1994.
} 
português e, consequentemente, dos seus artistas e escritores. Para ele, Portugal era um país onde "os inovadores são ignorados ou insultados com a mais imbecil obstinação" (Hourcade, 1931: 5). Contudo dois grupos resistiam e mereciam particular atenção, prosseguia Hourcade. O primeiro era constituído por Fernando Pessoa, Mário de Sá Carneiro e Almeida Negreiros; o segundo pelos principais membros da revista Presença que prometiam igualar e ultrapassar os primeiros "pela riqueza e variedade dos seus dons, força e a independência dos seus espíritos", conforme o crítico francês pressupõe ${ }^{5}$.

Sete anos mais tarde, o mesmo autor publicava, na revista Yggdrasil, um artigo, "Panorama de la poésie portugaise moderne", no qual caracterizava, sinteticamente, a poesia portuguesa dessa época como dominada pelo elemento espiritual e o gosto pelo irremediável, destacando os nomes de Fernando Pessoa e José Régio ${ }^{6}$. Opinião mais tarde repetida por outros observadores. Porém, só vinte e dois anos depois da publicação do artigo que, no início, referimos, o nome de José Régio voltará a ser evocado para o leitor francês, desta vez, nos jornais parisienses de maior divulgação; isto porque o público parisiense se preparava para assistir, na noite de trinta e um de dezembro de 1952, à estreia mundial de Jacob et l'Ange (Jacob e o Anjo), peça cuja publicação o autor iniciara cerca de vinte anos antes na revista Presença ${ }^{7}$. Representar em Paris num teatro de renome como era então o Studio des Champs-Elysées iria, obviamente, expor José Régio ao parecer dos intelectuais em voga e dos críticos teatrais. Se os primeiros sentenciam, atribuindo ou negando mérito a uma obra em função de critérios pessoais, mais ou menos determinados por escolas e modas literárias, os segundos detêm-se, em geral, menos no texto e mais na representação que dele se faz. Jacob e o Anjo foi, portanto, recebida de forma diversa pela crítica, consoante a sensibilidade e o interesse de cada um dos observadores. De forma diversa, mas nunca verdadeiramente entusiasta, a peça, que só a boa vontade dos seus participantes permitiu levar à cena ${ }^{8}$, acabaria por ter um número reduzido de representações durante os primeiros dias do ano de 1953.

Para os intelectuais, Francis Ambrière, Jacques Audiberti, Gabriel Marcel, a peça apresentava sérias deficiências formais, mostrando assim claramente que José Régio não era um dramaturgo. Para eles, entre outros aspectos, Régio "confundia o teatro com uma escola de metafísica" (Ambrière, 1953: 43), conforme escreve o prestigiado Francis Ambrière na revista Coemedia. Ora se considerarmos que Ambrière tinha sido galardoado

\footnotetext{
${ }^{5}$ Artigo logo traduzido e publicado por João Gaspar Simões, que aproveita o ensejo para mostrar aos críticos nacionais a importância do artigo de Pierre Hourcade: "Enfim há alguém em França, que nos olha e compreende com olhos vivos, olhos de artista e de crítico- que não de erudito. Infelizmente, temos sido sempre vistos através dos "documentos ( Presença, no30, 1931:13-14).

6 Bruxelas, Agosto de 1938.

7 "Em cenários de veludos escuros da autoria de Jean Denis Maillart, com figurinos indeterminados no tempo de Marcel Petitjean, numa encenação de Jacques Charpin” (apud, Neves, 1953:9).

8 Relembramos, a esse propósito, que os artistas envolvidos superaram importantes dificuldades financeiras.
} 
em 1946 com o prémio literário Goncourt (uma inegável referência interna para as letras francesas) não é difícil supor o efeito das suas palavras junto do público.

Igualmente influente era também o multifacetado dramaturgo Jacques Audiberti que, na crónica publicada no semanário $A r t s^{9}$, ironiza sobre as personagens da peça que, segundo ele, pecavam pelo seu psicologismo lírico e os seus diálogos metafísicos ${ }^{10}$. Afirma ainda que o anjo, como o Messias e os apóstolos, se exprimia de maneira enervante, peremptória, parabólica e superior: "Ils s'expriment comme le Messie et les apôtres, de la manière la plus agaçante, avec un air d'en savoir long. Obscur, péremptoire, parabolique et supérieur" (apud Rodrigues, 1986: 164).

Curiosa observação, acrescentamos nós, por parte de um autor descrito como tradicionalista na forma, "cuja profusão e truculência verbal exprimem uma humanidade patética, gloriosa, terna e sarcástica" (Leuilliot; Décaudin, 1984: 134), conforme é geralmente apresentado ao leitor francês ${ }^{11}$. Porém, de todas as críticas a mais séria e pertinente parece ter sido a do inquestionável mestre do existencialismo cristão francês, o filósofo e dramaturgo Gabriel Marcel, autor cujas preocupações metafísicas apresentam bastantes afinidades com as de José Régio. Insistindo, como Jacques Audiberti, na inverosimilhança e na incongruência das personagens de Jacob e o Anjo, Gabriel Marcel afirmava, na sua crónica publicada em 15 de Janeiro na Nouvelles Littéraires, não entender como podia José Régio ter materializado a personagem do Anjo do sonho e atribuir características evangelistas ao bobo. Por outro lado, aquele que fora crítico literário e musical da prestigiada revista NRF (indiscutível referência para os autores da Presença) considerava ainda que o espectador só no terceiro acto, e muito esporadicamente, sentia alguma emoção: "Mais il faut bien avouer que le spectateur n'éprouve une émotion quelconque qu'en des très rares instants du troisième acte" (Marcel, 1953: 9).

Se as palavras dos restantes críticos (então reproduzidas em jornais portugueses por Urbano Tavares Rodrigues e Luís Francisco Rebelo, entre outros, nas suas crónicas de Paris enviadas) não mereceram qualquer reacção por parte de Régio, o mesmo não aconteceu com a crítica de Gabriel Marcel. Tão importante era que José Régio considerou oportuno dar-Ihe uma merecida resposta que intitulou "Comentário sobre um comentário de Gabriel Marcel", publicada no Jornal de Letras, Artes e Ciências em março desse mesmo ano. Aí, "texte à l'appui", o autor de Jacob e Anjo refuta uma a uma as debilidades que Gabriel Marcel apontara ao texto para justificar a sua crítica e conclui que as observações de Gabriel Marcel só se explicavam pelo desconhecimento que o crítico francês tinha da

\footnotetext{
9 Arts de 9 a 16 de Janeiro de 1953.

10 Jacques Audiberti, então autor de sucessos, alguns no teatro, seria mais tarde colaborador des Cahiers du Cinema antes de ser contemplado com o "Grand Prix National des Lettres".

${ }_{11}$ "Son jaillissement verbal, sa truculente abondance s'accommodent de la prosodie traditionnelle, voire des formes fixes, pour exprimer un univers toujours en fusion et une humanité pathétique, à la fois glorieuse, tendre, dérisoire", in: Anthologie de la poésie française, Paris, Gallimard, 1984.
} 
peça e da literatura portuguesas ${ }^{12}$. Para o poeta de Vila do Conde, se críticas havia a fazer, estas poder-se-iam atribuir, não propriamente à peça, mas à adaptação que dela fizera J.B. Jeener $^{13}$. Ferido no seu orgulho de autor, a reacção de José Régio revela a importância por ele atribuída à crítica de Gabriel Marcel, crítica que não hesita em reproduzir, " mot à mot", a fim de demonstrar como a considerava injusta e sem verdadeiro fundamento. Para melhor contrariar a observação do filósofo francês, que apontava para as debilidades formais de Jacob e o Anjo, cita-o longamente e responde-lhe ponto por ponto, como se pode verificar no exemplo seguinte, constituído pela crítica e a sua refutação:

Je serais justement tenté de dire que les auteurs, comme si souvent au théâtre, ont péché par manque de réflexion. II ne me semble pas s'être rendu compte que ce bouffon, qui n'est pas un, est un être de raison qui ne peut en aucune manière, participer à une action dramatique et que, dans ces conditions, nous avons le sentiment d'assister plus à une espèce de joute rhétorique qu'à un drame (Régio, $1953: 9)$.

Retenhamos as seguintes afirmações [escreve o criticado]:

A $1^{\text {a }} \mathrm{O}$ bobo não é um bobo;

$2^{\mathrm{a}}$ é um ser imaginário (un être de raison);

$3^{\text {a }}$ um ser de tal espécie não pode de maneira nenhuma participar num drama;

$4^{\underline{a}}$ em tais condições, temos antes o sentimento de assistir a uma

espécie de torneio retórico"(Régio, 1953: 6).

Partindo desta constatação, Régio defende-se e reclama o seu direito de criador, o direito de ser ambíguo, pois para ele a ambiguidade é inerente à criação artística: "a ambiguidade é uma daquelas coisas que estão profundamente enraizadas na íntima personalidade de um artista criador". E acrescenta ainda que "lutando com o seu bobo o rei luta consigo próprio" (Ibid). Estupefacto com as palavras de Gabriel Marcel, José Régio confessa até que o seu pasmo tinha subido ao rubro ao ler a afirmação do crítico francês quando este refere que as personagens da peça eram pouco credíveis e em nada contribuírem para a plenitude teatral da mesma:

\footnotetext{
12 Desconhecimento reconhecido pelo próprio Gabriel Marcel que Régio comenta da seguinte maneira:

" Começa G. Marcel por duas honestas declarações, a de tudo ignorar sobre o autor de Jacob e o Anjo, sem dúvida estará mais apto a compreender Jacob e o Anjo quem tenha algum conhecimento das minhas outras obras"; e até do teatro português em geral, principiando pelo de Gil Vicente, a segunda a de ser muito difícil julgar o valor de uma obra poética traduzida" (Régio, 1953: 6).

${ }_{13}$ Adaptação que o próprio Régio confessa desconhecer na totalidade, embora acrescente não crer ter havido uma profunda transformação no texto apresentado ao público: "Não creio porém que Jacob e o Anjo sofresse uma deformação capaz de justificar certas observações de G. Marcel". (Ibid)
} 
il faut dire que les personnages [...] non seulement n'apportent quoi que ce soit qui ressemble à une plénitude théâtrale mais au contraire y créent une sorte de fastidieux encombrement" (Régio : 1953 :10).

José Régio insiste então em demonstrar neste seu longo "Comentário sobre um comentário de Gabriel Marcel' que o crítico falava em abstracto: "Mais uma vez, Gabriel Marcel não fala da minha peça: mas de uma abstracção pela qual a substituiu" (Régio, 1953: 4). Argumento que o leva a terminar de forma peremptória e altiva, numa atitude própria de quem se sentiu desvalorizado: "Isso me obriga a terminar este comentário duma maneira "un peu hautaine" (ibid). Pelas suas palavras, verificamos que José Régio reagiu com ressentimento à incompreensão que a sua peça parece ter encontrado junto dos intelectuais franceses da época.

Com menor influência no tempo junto do público, as observações dos críticos de teatro sobre a peça de José Régio, publicadas pelos jornais diários, apenas se diferenciam pelos adjectivos que os seus autores entenderam por bem utilizar para caracterizar as representações de Jacob e o Anjo. Todos, apesar de algumas reservas que adiante mencionaremos, aconselhavam o público a deslocar-se ao Studio des Champs-Elysées. Assim, Marcelle Capron, recorrendo a uma adjectivação muito vaga, aconselhava, na sua crónica do diário Combat, o público a ir ver a peça por se tratar de uma obra importante e bem adaptada:

Não conto a peça que vos aconselho a irem ver, ela é importante [...] a adaptação de J. B. Jeener guardou toda a sua força e solidão, ao mesmo tempo que a sua elegância e o seu espírito (apud, Neves, 1953: 9).

Por seu lado, o crítico do vespertino France Soir, Marc Blanquet, afirmava que José Régio era um autêntico dramaturgo: "A obra é de um dramaturgo autêntico" (ibid). Opinião confirmada por André Rassan que nas páginas do matutino Ce Matin considera o tema da peça patético e de grandiosidade moral, "patético com uma grande nobreza de pensamento" (ibid).

Das observações que acabamos de ler constatamos um desajuste de vozes entre escritores e críticos de teatro. Para os primeiros a peça era um fiasco, para os outros um recomendável espectáculo. Neste desacerto de vozes, um aspecto houve que conseguiu a unanimidade: a fraca interpretação dos actores.

Com efeito, Marc Beigdeber (como Gabriel Marcel o referira na Nouvelles Littéraires) escreve no Parisien Libéré que "a peça teria pedido uma interpretação de primeiríssima 
grandeza", dando, portanto, a entender que a não teve. O crítico do France Soir lamenta, por seu lado, "que uma tal obra não tivesse sido montada com os meios que exigiam o seu autor e a sua qualidade" (Rebelo, 1953: 9). Esta observação é no mínimo curiosa tendo em consideração que José Régio era praticamente desconhecido do público francês; a menos que o crítico do France Soir conhecesse a língua portuguesa, o que duvidamos. Jean Jacques Gautier no Figaro constata que, exceptuando aquele que representava o AnjoBobo, os actores se limitavam a recitar as frases. Crítica em geral atribuída aos amadores e não a actores profissionais habituados a um público exigente.

O fraco desempenho dos actores sobre o qual recaíram as críticas é também salientado por dois escritores portugueses, Luís Francisco Rebelo e Urbano Tavares Rodrigues, que assistiram às representações da peça e sobre elas teceram igualmente comentários. Urbano Tavares Rodrigues escreve mesmo que a actriz Françoise Adam (anos mais tarde considerada como uma figura de referência na arte representativa em França) diminuía o papel da rainha que interpretava: "enquanto ao papel da rainha afigura-se-me que a interpretação (Françoise Adam) o diminui" (Rodrigues, 1961: 34).

Perante uma tal unanimidade sobre a sua interpretação os actores reagiram, contrapondo que os críticos não tinham entendido a peça sobre a qual teciam comentários. Um desses actores, Luís de Lima (que representava o poeta da corte), confessava que, embora o público os tivesse bem acolhido, os críticos "se tinham agarrado ao resumo do programa e à volta dele tecido considerações". E Jacques Charpin, encenador e actor principal, declarava que "poucos jornalistas tinham compreendido a peça" (apud. Neves, 1953: 9).

Destas observações uma constatação se impõe: ou a peça era demasiado inovadora para a crítica que, por diversas razões, não a entendeu, inclusive culturais, ou então não correspondia ao que o público de teatro estava no direito de exigir, ficando qualitativamente aquém do esperado. Seja como for, influenciado pelo que ia lendo, o próprio José Régio acabaria por reconhecer (embora não tenha assistido a qualquer representação), numa carta enviada a Jorge de Sena, que a companhia de teatro não tinha experiência necessária para realizar um projecto dessa envergadura ${ }^{14}$.

Para melhor compreendermos e situarmos a importância das reacções que a representação da peça de José Régio suscitou devemos considerar que, por essa altura, os teatros parisienses apresentavam peças de Garcia Lorca, Eugène Ionesco, Samuel Beckett, Adamov, Jean Anouilh, Jean-Paul Sartre e que os mais representativos autores franceses da segunda metade do século publicavam seus romances ou ensaios ${ }^{15}$. O dramaturgo José Régio que, na altura, se declarava, não sem exagero, "como um modesto representante de

\footnotetext{
${ }^{14}$ Citado por Rodrigues, in "La solitude".

${ }^{15}$ Entre muitos, poderíamos citar Marguerite Duras, Albert Camus, Marguerite Yourcenar e Roland Barthes.
} 
uma das literaturas mais desconhecidas do mundo" (Régio: 1953: 5), foi pois, durante um curto período de tempo, comparado com os grandes nomes do teatro e da literatura europeia da primeira metade século XX.

Em suma, bem ou mal recebida, a representação de Jacob e Anjo não passou despercebida, e, se outro mérito não tivesse, chamou indiscutivelmente a atenção do público francês para a existência de uma dramaturgia portuguesa até então quase ignorada em França.

De todos as reacções que a peça de José Régio suscitou, e do muito que sobre ela se escreveu, seria de supor que os editores franceses investissem na publicação de, pelo menos, algumas das obras do autor de Poemas de Deus e do Diabo. Porém, nada disso aconteceu e José Régio teria de esperar mais dez anos para ver o seu nome referido na Histoire Générale des Littératures, obra de referência publicada em Paris em 1961. Aí, é sumariamente apresentado por Michel Corneille como um místico, provavelmente o mais conhecido dos colaboradores da Presença, "un mystique, probablement le plus connu des collaborateurs de la revue Presença ", e que as suas últimas obras lhe asseguravam um apreciável reconhecimento ${ }^{16}$. Referência que evidencia um conhecimento superficial do autor e da sua obra, mostrando, por outro lado, que as criticas dos intelectuais franceses que tinham rotulado Régio de místico ainda surtiam efeito, pois permaneciam na memória dos historiadores literários.

Publicada dez anos depois, surge no mercado francês uma Anthologie de la Poésie Portugaise, obra que reúne oito séculos da poesia nacional, dos trovadores ao surrealismo. Aí José Régio é apresentado ao leitor de maneira mais fundamentada. Isabel Meyreles, tradutora e organizadora da antologia, escreve no prefácio, datado de 1961, que José Régio é uma figura gigantesca da moderna literatura, não apenas pela sua poesia, mais pelo conjunto da sua obra que é o cume da ficção e da dramaturgia atual, baseando-se o seu teatro no diálogo entre as forças do bem e do mal no cruzamento das quais o homem reflecte sobre o seu destino ${ }^{17}$. A tradutora relembra, em seguida, ao leitor que José Régio foi representado em Paris (Meyreles, 1961: 12), e inclui dois poemas, um deles traduzido em 1952 por Pierre Hourcade ${ }^{18}$. Os poemas em questão são: Le poète Fou, le Vitrail et la Sainte morte e Fado-Canção.

\footnotetext{
16 "Ses dernières compositions, Mais Dieu est Grand et La Plaie à côté, 1954, lui ont valu une appréciable renommée" (Corneille, 1961: 564).

17 "C'est aussi sous le signe dramatique que se place l'autre grand poète de Presença, José Régio, figure gigantesque de la moderne littérature, non seulement pour sa poésie mais aussi par l'ensemble d'une œuvre qui comprend les sommets de la fiction et de la dramaturgie actuelle. Mais avec José Régio, la dramatisation qui le mène au théâtre vient du dialogue entre les forces du bien et du mal au croisement desquels l'homme réfléchit sur son destin".

18 Lembremos que Pierre Hourcade era primo do colaborador do Fígaro, J. B. Jeener, o mesmo que tinha adaptado Jacob e o Anjo, ponto de partida para a apresentação ao público parisiense da mesma peça.
} 
Já depois da morte de José Régio, a mesma tradutora, Isabel Meyreles (igualmente poeta), publica, de novo em Paris, na revista Bicephale: Europe-Amérique Latine (1982), uma tradução da Toada de Portalegre, "Complainte de Portalegre". Num número dedicado a Portugal e ao Brasil, José Régio aparece depois de Mário Sá Carneiro, Almada Negreiros e antes de Cruzeiro Seixas ${ }^{19}$. Isabel Meyreles relembra ainda que José Régio fora professor do liceu de Portalegre durante quarenta anos e o mais representativo dos poetas da sua geração.

Com estas sucessivas e esporádicas referências se preparava o terreno para a publicação, desta vez em livro, de duas obras de José Régio: uma antologia poética e o romance Jogo da Cabra Cega, editados em 1995 e 2001, respectivamente. Até estas datas, não encontrámos edição alguma em livro de obras de José Régio em francês. Prefaciada por Robert Bréchon (um dos tradutores e biógrafos franceses de Fernando Pessoa), esta antologia, com o título Fertile Désespoir, surge no mercado francês num momento propício para as letras portuguesas ${ }^{20}$. Com efeito, Fernando Pessoa gozava finalmente de um interesse generalizado, facto que se traduzia num reconhecido sucesso editorial. Assim, talvez por essa razão, Robert Bréchon insiste tanto em demonstrar ao leitor francês que José Régio tinha sido o discípulo predilecto do poeta da Mensagem ${ }^{21}$. Demonstração que o leva ainda a reproduzir na contracapa uma citação relativa a José Régio de um artigo de Fernando Pessoa sobre a moderna poesia portuguesa, artigo de que destaca a seguinte afirmação: "ele [José Régio] é o melhor de todos, primus inter pares" (Bréchon, 1995: 7). Nos parágrafos seguintes, o prefaciador salienta igualmente a consciência profissional de Régio: “il a mené jusqu'à son terme, avec la plus grande conscience professionnelle, une carrière de professeur de lycée" (ibid). Explica ainda o que, no seu entender, distingue Régio e a poesia da Presença dos poetas do Orfeu: "Ao trágico ontológico de Pessoa e Sá Carneiro sucede um trágico existencial"(ibid).

Com o objectivo de ajudar o leitor francês a melhor entender e a contextualizar a obra de José Régio, Robert Bréchon, que exercera a docência em Lisboa nos anos cinquenta, estabelece várias comparações entre Régio e alguns dos mais prestigiados autores franceses: Baudelaire, Victor Hugo, Rimbaud, Gide, Malraux, Albert Cohen e Claudel. Chama aí a atenção do leitor para o facto de a filosofia dos presencistas ter precedido de alguns anos o "personnalisme" de Emmanuel Mounier em França, filosofias

\footnotetext{
19 No prefácio da revista, o director, François Castex (igualmente tradutor e biografo francês de Mário de Sá Carneiro), referindo-se às dificuldades relacionadas com a sobrevivência da revista, escreve : "Nous sommes suicidaires".

${ }^{20}$ Título dado a uma selecção de poemas, traduzidos por Isabel Meyreles, extraídos de sete dos livros de José Régio e dois poemas dispersos em revistas. Bordeaux, L'Escampette, 1995.

Convém relembrar que, por essa altura, era grande o esforço feito para a promoção da literatura portuguesa em França, país que conta com o maior número de traduções de autores portugueses, são mais de 300 os títulos publicados a partir da década de 80 .

21 "Régio, comme son maître Pessoa, met son être en scène dans son œuvre, qu'elle soit lyrique, romanesque ou dramatique".
} 
que, segundo o crítico, apresentam bastantes afinidades ${ }^{22}$. Não obstante todos escritores citados, o prefaciador considerava que Pierre-Jean Jouve era o autor francês que mais se aproximava de José Régio: "Pierre-Jean Jouve, le poète français dont José Régio me paraît le plus proche" (Bréchon, 1995: 10).

Insistindo sempre em comparações com Fernando Pessoa, Bréchon acrescenta, mais adiante, que José Régio vivia fascinado pelo "au-delà", ou seja, por um inacessível além, e que abandonara, com o tempo, a subjectividade inicial para tornar mais humana a sua obra: "Subjective à ses débuts l'œuvre de Régio, au fil des ans, assume de plus en plus de l'humanité" (ibid). A fim de justificar a sua opinião, cita como exemplos dessa evolução os poemas Fado des pauvres e Fado des femmes de mauvaise vie. Observação que o leva, uma vez mais, a comparar José Régio aos seus contemporâneos franceses, desta vez os surrealistas que, tal como o poeta português, ambicionavam viver neste mundo a experiência espiritual que as religiões situam no além:

Ces lignes [...] rapprochent Régio de ses contemporains français, les surréalistes, dont toute l'ambition a été de rapatrier ici-bas l'expérience spirituelle dont les religions ont situé l'objet dans un au-delà" (Bréchon, 1995 : 12).

O segundo livro de José Régio editado em França, o romance Collin-maillard (Jogo da Cabra Cega), tem como prefaciador uma figura portuguesa igualmente reconhecida internacionalmente: Manuel de Oliveira. Artista cujo prestígio em França poderia contribuir junto dos seus admiradores para uma mais rápida aceitação do romance agora publicado.

Lembrando que convivera com o autor desde os tempos da revista Presença, o cineasta começa por afirmar que o romance em questão era o livro mais singular de toda a produção romanesca de José Régio. Uma obra que, pela sua modernidade, constituía incontornável referência da expressão romanesca em Portugal: Collin- maillard est un des pionniers de la modernité d'une nouvelle expression Romanesque" (Oliveira, 2000:10).

Manuel de Oliveira faz igualmente questão de informar o leitor que o autor lhe tinha confidenciado que algumas situações descritas no romance eram a consequência da própria experiência do poeta: "Je sais, par exemple, que certains passages de Collin-maillard ont été inspirés par des scènes qu'il avait vécues" (Ibid). Informações que the permitiam dar mais peso à opinião que agora formulava. Por outro lado, o cineasta escreve que a figura do poeta representava o mais cabal conceito da intelectualidade da época, próprio de um artista e pensador completo, multifacetado, com talentos tão diversos que, por vezes, se ofuscavam uns aos outros:

22 "La philosophie du mouvement "présenciste", dont il [José Régio] est le principal inspirateur, est un "personnalisme", qui précède de plusieurs années celui d’Emmanuel Mounier en France". 
La reconnaissance unanime du poète devait plus tard faire obstacle à la compréhension de son œuvre romanesque, tant avait été profonde l'impression laissée par ses premiers vers (Ibid).

Para melhor se compreender o romance em questão, Manuel de Oliveira acrescenta ainda que José Régio tinha um espírito profundamente religioso em permanente e insolúvel conflito entre fé e razão. Dilema que lhe provocava uma dúvida angustiante, um estado de espírito que a sua poesia e o seu teatro, nomeadamente em Jacob e o Anjo e Benilde ou a Virgem Mãe, deixam transparecer.

No entanto, tal como Robert Bréchon o referira já, Manuel de Oliveira era também obrigado a constatar que José Régio permanecia, apesar da inquestionável grandeza da sua obra, um autor esquecido e desconhecido, por razões que o cineasta não saberia explicar:

Malgré cela, pour des raisons qui nous dépassent, l'oubli forcé auquel semble voué le poète, s'acharne sur l'essayiste, le romancier, le dramaturge, le penseur et, dans ce cas, le prophète (Oliveira : 2000 :12).

Salientando a integridade, generosidade, dignidade e sinceridade do poeta, o cineasta decide concluir a sua introdução com alguns versos extraídos do poema Praça Pública, significativos em seu entender do autor e da sua obra:

Qui ne me laisse pas être moi?

Vivre, c'est pour moi, douter [...]

Saisir la fumée entre les mains,

Et faire signe à des frères que j'ai

Que je sens proches, et que je ne vois pas

À cause de la foule ${ }^{23}$ (Ibid).

Contudo, apesar de os editores terem procurado despertar o interesse dos críticos e dos leitores, associando o nome José Régio a duas figuras reconhecidas no mercado cultural francês, não encontramos qualquer reacção digna de registo por parte dos críticos literários sobre as obras em questão. Facto que talvez possamos explicar por estas terem sido publicadas por editores relativamente pequenos não dispondo na complexa actual

\footnotetext{
${ }^{23}$ José Régio «Quem me não deixa ser eu?!» in Poemas de Deus e do Diabo: Viver, é para mim, duvidar,/ Desvairar,/ Interrogar,/ Procurar-me,/Torturar-me,/ Agarrar fumo nas mãos, / E acenar a uns meus irmãos / Que sinto perto, e não vejo / Por causa da multidão... (Régio, José, 2006: 23).
} 
indústria do livro dos mesmos argumentos e recursos financeiros que outros grandes grupos. Por outro lado, verificamos igualmente que, salvo raras excepções, o maior contributo para a divulgação da obra de José Régio em França ficou a dever-se a alguns críticos portugueses redigindo em francês. Entre eles, justo é destacar o nome de Isabel Meyreles que, na segunda metade do século XX, dedicou uma particular atenção à divulgação da obra do poeta. Tarefa nem sempre fácil, como vimos ao longo destas linhas, mas decisiva, pois foi inegavelmente preparando o leitor francês para que, em 2002, Eduardo Prado Coelho pudesse apresentar na Enclyclopedia Universalia, José Régio como o poeta da exaltação narcísica e retórica, um autor capaz de cabalmente exprimir as complexas contradições que definem o sujeito, remetendo o leitor para as obras então em França publicadas: "Poète à l'exaltation narcissique et rhétorique, auteur d'une fiction capable d'exprimer les contradictions morales, religieuses et sexuelles du sujet - Jogo da cabra cega" (Coelho, 2002: 680).

Setenta anos depois da publicação da primeira referência à obra de José Régio em França, constatamos que este continua por descobrir em França, e que as reações que a sua obra suscitou revelam uma interpretação que raramente considerou o contexto que the é indissociável. Ora, conforme o próprio refere, a obra de José Régio, isolada do chão que a viu nascer, é como uma árvore sem raízes. 


\section{Bibliografia}

BRECHON, Robert (1995). “Préface”, in Fertile Désespoir. Bordeaux : L'escampette, pp. 7-15. COELHO, Eduardo Prado (2002). “ José Régio”, in Enclyclopedia Universalia, Paris, v.18, p. 680 .

CORNEILLE, Michel (1961). “José Régio”, in Histoire Générale des Littératures, tv. VI. Paris : Librairie Aristide Quillet, p. 765.

FRECHES, Claude Henri (1986). "Le Théâtre Portugais en France au XXème siècle", in Arquivos do Centre Culturel Portugais. Paris: F.C.Gulbenkian, pp.251-259.

LEUILLIOT, Bernard. e DECAUdIn, Michel (1984). Anthologie de la poésie française. Paris :

Gallimard.

MEIRELES, Isabel (1962). “Complainte de Portalegre”, in Bicephale: Europe-Amérique Latine, nำ78, pp. 38-45.

NEVES, João Alves das (1953). “Apresentação em Paris de Jacob e o Anjo”, in Jornal de Letras Artes e Ciências, nำ11, p.9.

OliveIRA, Manuel de ( 2000). "Introduction", in Collin-maillard, Paris : ed. Métailié, pp. 9-13.

RÉGIO, José (1953). “ Comentário sobre um comentário de Gabriel Marcel”, in Jornal de Letras, Artes e Ciências, ano 1, nำ12, pp. 6-7. (2006). Poemas de Deus e do Diabo, Lisboa: Quaso ed.

RIVAS, Pierre (1995). Encontro entre Literaturas, França-Portugal- Brésil. S. Paulo: Ed. Hucitec.

RODRIGUES, Urbano Tavares (1986). "La solitude, l'absurde et le dialogue dans l'œuvre de José Régio", in Arquivos do Centro Cultural Português. Paris: Fondation Calouste Gulbenkian, pp.167-174.

TeYssien, Paul (1985). "Memoriam”, in Bulletin des Etudes Portugaises, no 44-45, Paris : Ed. La Sorbonne, pp.429-437. 
